
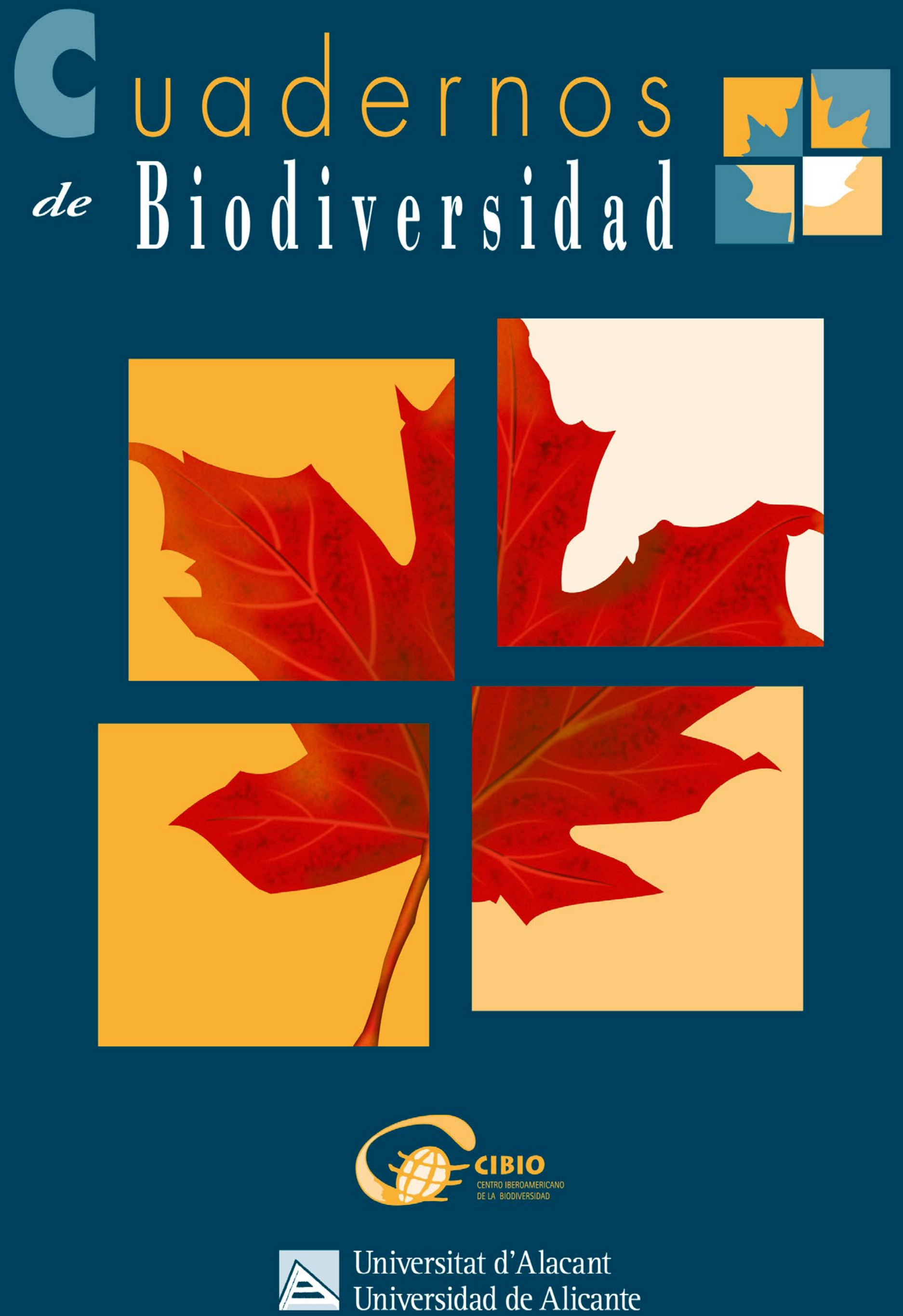


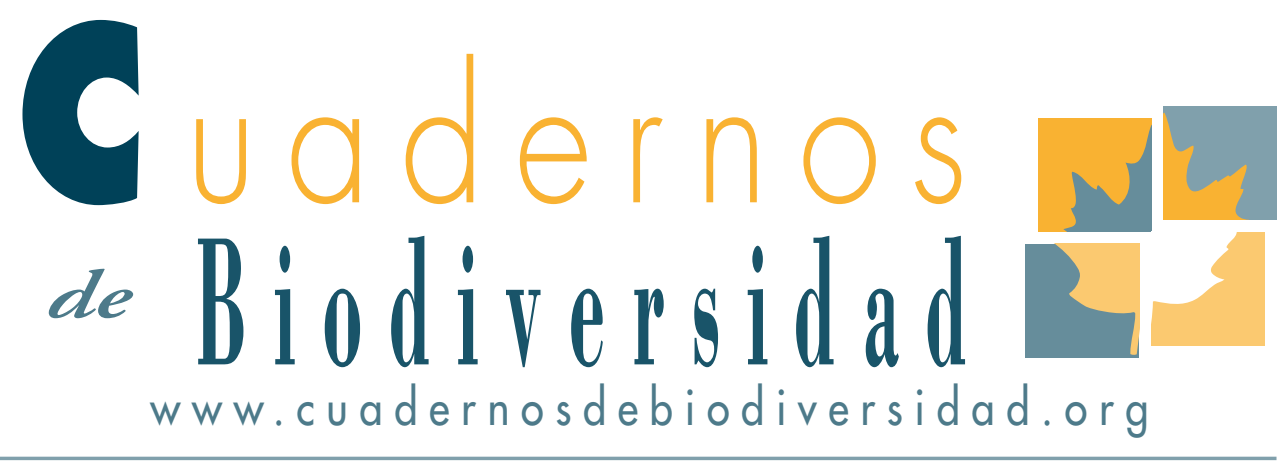

\title{
Extinciones históricas: el caso de la enigmática planta del Silfio
}

\section{Segundo Ríos Ruiz}

\author{
Estación Biológica-Jardín BotÁnico Torretes \\ Instituto de Investigación Cibio. Universidad de Alicante
}

\section{ABSTRACT}

This review refers to the Silphium (Apiaceae), one of the most enigmatic plants in the history of the Mediterranean. In Greco-Roman world, it was a panacea and especially, a powerful aphrodisiac which left many written historical references, in addition to their image mosaics and coins. Silphium extinction, due to over-exploitation is certainly a good example for the conservation of biodiversity and for the defense of sustainable use of natural resources

Key words: Silfio, Ferula, Apiaceae, Cirene, Santorini, Conservation.

\section{INTRODUCCIÓN}

La desaparición de especies raras o endémicas es un tema que está de actualidad y son muchas las causas naturales que afectan negativamente a la biodiversidad y pueden llevar a las especies a su extinción. Pero aparte de las causas naturales, son las actividades humanas las que con mayor frecuencia sobreexplotan el medio natural y producen en él cambios tan drásticos e irreversibles que impiden la supervivencia de muchas especies. Además, cuando alguna especie se constituye en un importante recurso económico, si su explotación no es sostenible, puede abocar en su extinción.

A lo largo de la historia humana, esto ha ocurrido en muchas ocasiones y sigue siendo, por desgracia, una amenaza para la biodiversidad presente y futura. Son dos buenos ejemplos de especies que se han llevado al borde de la extinción en tiempos recientes, los casos del Palosanto o Lignum vitae (Guaiacum sanctum L.) un árbol de Centroamérica (México, Guatemala), las Antillas y el Caribe (Cuba, Venezuela, Guayanas; etc.) y por otro lado el caso del Pigeón (Prunus africana (Hook f.) Kalkman) un árbol emparentado con el laurel-cerezo europeo (Prunus laurocerasus L.), pero de origen africano. Del Palosanto ya eran utilizadas su madera y resina como 
medicinas indígenas precolombinas, las cuales fueron difundidas y distribuidas por los españoles para el tratamiento de la sífilis en toda Europa. Además, su madera era y es muy valiosa para la ebanistería y la fabricación de instrumentos musicales. Del segundo, se exportaron durante siglos toneladas de su corteza desde África a toda Europa para tratamientos de las disfunciones de la próstata, entre otros usos medicinales.

En la actualidad el comercio de ambas está regulado por el acuerdo internacional CITES, estando el Palosanto en el Apéndice I y el Pigeón en el Apéndice II de dicho tratado. También la UICN considera ambas especies en peligro de extinción en las categorías de EN y VU respectivamente. Son pues dos buenos ejemplos de lo que el uso abusivo de los recursos naturales no renovables puede producir y como se deben vigilar estos casos en origen, exigiendo medidas de protección o promoviendo su cultivo como una ayuda al desarrollo local.

Pero la utilización abusiva de los recursos naturales que se considera un tema de actualidad, es tan antigua como la propia especie humana. Un caso excelente para demostrarlo, gracias a la abundancia de referencias históricas y evidencias arqueológicas, es el de la misteriosa planta que los antiguos llamaban Silfio.

\section{ORIGEN E IMPORTANCIA DEL SILFIO}

Parece ser que, hacia el 630 a.C. unos griegos procedentes de la isla de Thera (actual Santorini), llegaron a la costa de Libia y fundaron la ciudad de Cirene en honor a la ninfa del mismo nombre. Proverbialmente, la colonia griega se instaló justo en el centro de distribución de una planta endémica, el Silfio, de la cual sabemos que perteneció al género Ferula sp. (Apiaceae), y que tenía gran interés comercial desde antiguo. Así que no es descabellado suponer que fue la posibilidad de controlar este recurso, lo que llevó a estos griegos a establecer la nueva ciudad allí.
A partir de entonces, el Silfio fue una verdadera fuente de riqueza pues de ella se usaban los frutos, la raíz y los tallos, pero sobre todo un jugo resinoso que exudaba la planta mediante cortes o incisiones y una vez precipitado constituía el también llamado laser o laserpicio.

Fue muy apreciada como culinaria y medicina, pero parece que fue su uso como afrodisíaco y anticonceptivo (y finalmente abortiva a dosis más altas), lo que le confirió un gran papel en la antigua cultura Greco-Romana (Fig. 1, Fig. 2). La resina precipitada de esta especie, una vez reducida a polvo, se podía ingerir con líquidos, hacer pastillas, espolvorear como especia, etc. Fue la principal fuente de riqueza de la ciudad de Cirene y su provincia, mediante su explotación intensiva durante 5 siglos hasta su total extinción en el s. I d.C. La explotación se basó exclusivamente en la recolección de las plantas silvestres, no habiendo constancia de que se consiguiese cultivar ni en su lugar de origen, ni en otras provincias del Imperio Romano, de manera que se supone que fue la sobreexplotación de un recurso endémico y escaso, lo que acabó extinguiéndola.

Algunas de las referencias históricas del último periodo de uso del Silfio son el asalto final a Roma por parte de Julio César (49 a.C.), los cronistas de la época cuentan que todavía halló unos $500 \mathrm{~kg}$ de esta especia depositados en la cámara del tesoro público. También en época de Plinio (s. I.), se describe la planta y su utilización, así como que era objeto de representación frecuente en las monedas. Parece que fue Nerón, por el año 60 d. C., quien pudo contemplar la última planta fresca de Silfio de que se tiene noticia. En el libro de cocina de Apicius "De Re Coquinaria" cuya fecha es imprecisa entre los siglos I-IV d.C., pues parece que el libro se fue rescribiendo por distintos autores posteriores, se menciona con frecuencia al Silfio, pero parece que ya entonces era adulterado por una de estas dos plantas o por ambas: otro "siler" europeo (Laserpitium siler L.=Siler montanum Crantz) o la asafétida (Ferula assa-foetida L.) de origen asiático. La primera de estas plantas aparece referida en el importante edicto imperial de Carlomagno (le Capitulaire de 


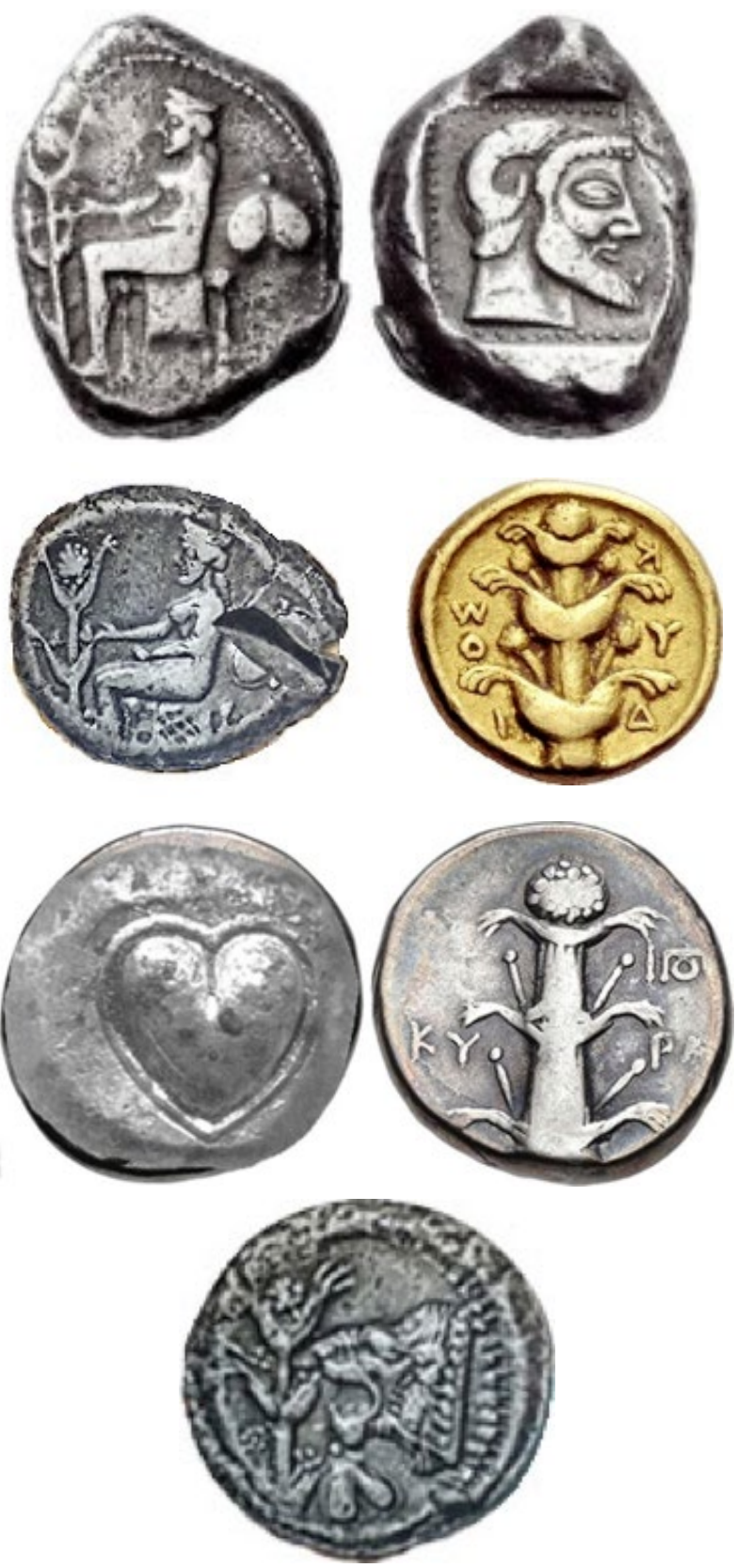

Figura 1: Presencia del Silfio en la numismática grecoromana (siglos $\mathrm{V}$ a.C.-I d.C.): representaciones de la planta y semilla del silfio, junto a la Ninfa Cirene sedente tocando con una mano la planta y con la otra sus genitales; dracma de oro con imagen del silfio; moneda con reverso representando las semillas del Silfio estilizadas en forma de corazón; tetradracma de Cirene mostrando sus símbolos de poder el león, la planta y semilla del silfio.

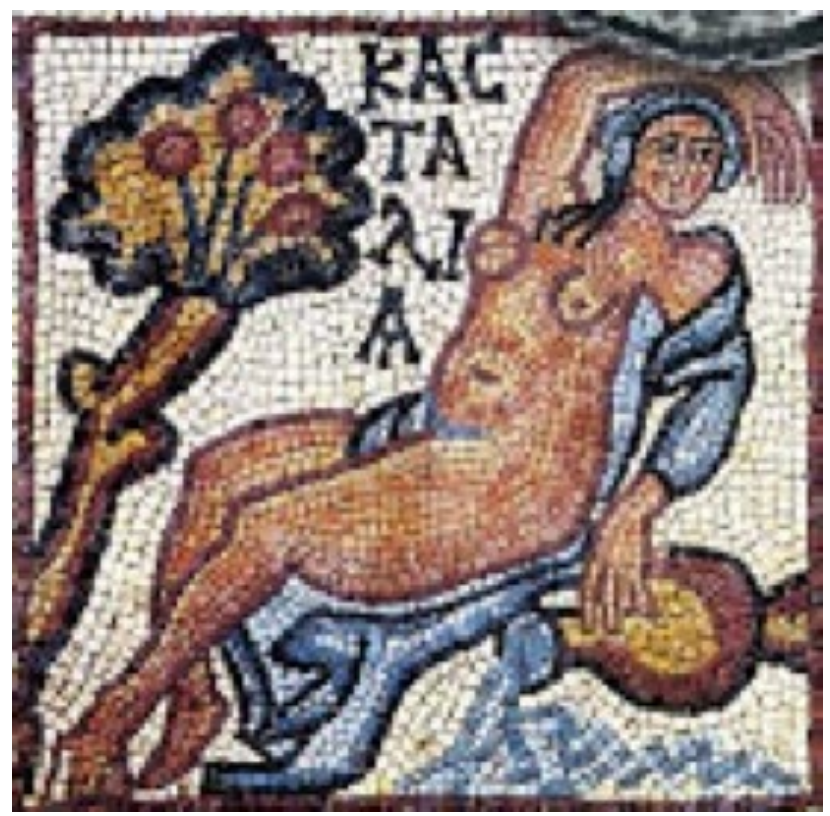

Figura 2. Mosaico de la Ninfa Cirene junto a la fuente Castalia de Delfos, lugar donde se realizaban los rituales de purificación previos a la realización del Oráculo. Muchas de las representaciones del Silfio, hacen una clara referencia a su uso ginecológico y sobre todo afrodisíaco a través de la imagen femenina en actitud de éxtasis.

Charlemagne o De villis vel curtis imperialibus s. VIII) y fue protegida y divulgada en sus dominios, permaneciendo todavía en su uso en toda Europa. La segunda conocida como asafétida, se difundió más por el Mediterráneo oriental y sigue siendo muy utilizada en la cocina turca, iraní, hindú, etc. En la India, la medicina Ayurvédica la recomienda con frecuencia como antihelmíntico, o sea, que combate los parásitos intestinales.

Pero si conocemos tanto de la morfología del Silfio, es gracias al detalle y buena calidad de las representaciones de la planta completa, de sus tallos con hojas, de las inflorescencias y de los frutos ("mericarpo" o agrupación de dos frutos secos típico de las plantas umbellíferas) en las acuñaciones de monedas en plata, oro y bronce. Son estas imágenes las que nos permiten aproximar su reconocimiento hasta el nivel de familia y género, pero a partir de ahí poco más podremos saber. 
Como testigos mudos del poder del Silfio y de su gran valor económico en el pasado, su imagen permanece en la heráldica y en el recuerdo de los países ribereńos mediterráneos que lo poseyeron o que lo disfrutaron (Fig. 3).
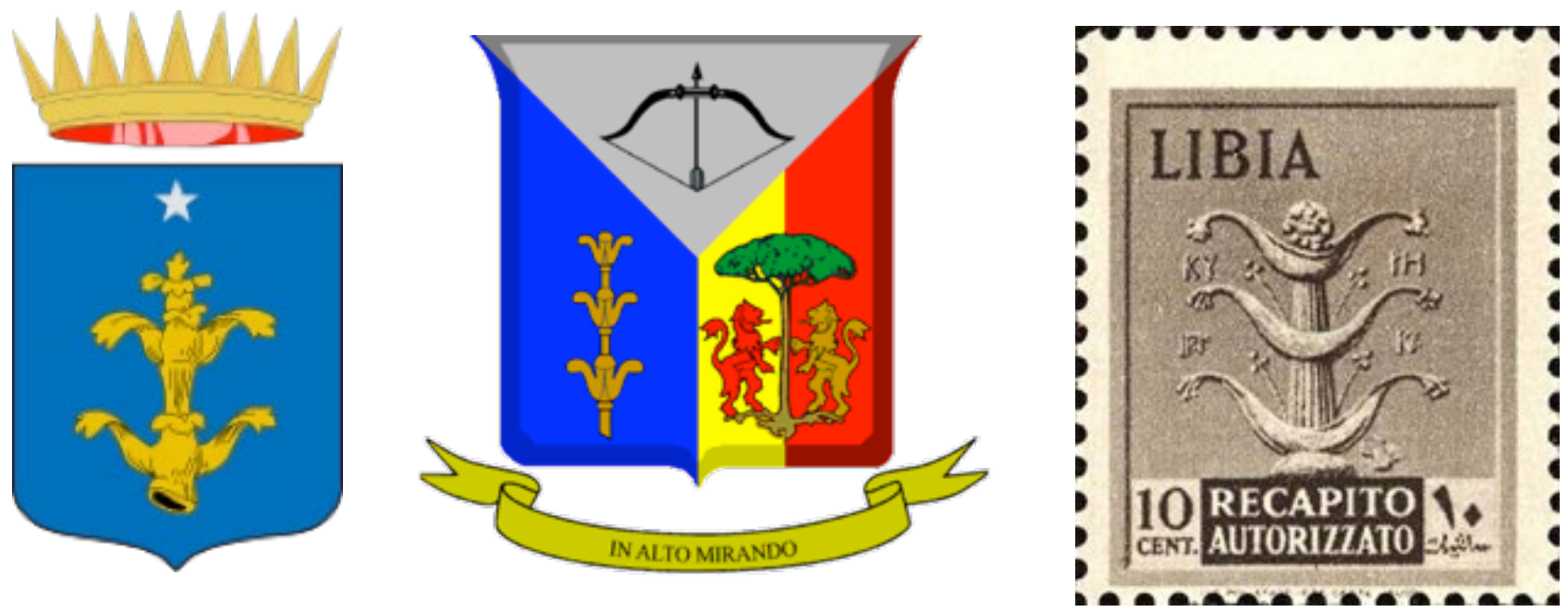

Figura 3. Presencia del Silfio en escudos de armas y timbres oficiales en Italia y Libia.

\section{CONCLUSIÓN}

La historia del Silfio es un buen ejemplo de lo que la explotación no sostenible de los recursos naturales puede provocar en aquellas especies que presentan un área de distribución reducida y con baja tasa de reproducción.

Con el Silfio la humanidad perdió probablemente una de las mejores plantas medicinales del Mediterráneo y que constituyó uno de los anticonceptivos naturales de mayor eficacia, pero su valor real nunca lo sabremos con certeza.

La conservación de nuestra biodiversidad siempre redunda en nuestro propio interés, pero es, precisamente, en el caso de las plantas medicinales donde la urgencia se hace necesaria y su importancia es mucho mayor.

\section{REFERENCIAS}

Apicius M.G. 1995. De Re Coquinaria. Gastronomía en la Antigua Roma Imperial. Ed. Sugar R\& B. 447 pp.

Gledhill D. 2008. The Names of Plants. Fourth Edition. Ed. Cambridge. 426 pp.

Pavord A. 2005. The Naming of Names. Ed. Bloomsbury pbks. London. $471 \mathrm{pp}$.

Van Wyk B-E. 2005. Food Plants of the world. An illustrated guide. Timber Press. Portland. 480 pp. 